\title{
Research article \\ Role of isosorbide mononitrate in induction of labour: A single arm clinical trial at a tertiary care hospital
}

\author{
Archana Sinha ${ }^{1}$, Sneh Kiran ${ }^{2 *}$, Sushant Sharma ${ }^{3}$, Dipali Prasad ${ }^{4}$, Sadia Parween ${ }^{5}$ \\ ${ }^{1}$ Additional Professor, ${ }^{2}$ Senior Resident, ${ }^{4}$ Associate Professor, ${ }^{5}$ Assistant Professor, Department of Obstetrics and \\ Gynaecology, Indira Gandhi Institute of Medical Sciences, Patna, Bihar, India \\ ${ }^{3}$ Associate Professor, Department of General Surgery, Sri Krishna Medical College and Hospital Muzaffarpur, Bihar, India
}

(Received: August $2020 \quad$ Revised: April $2021 \quad$ Accepted: May 2021)

Corresponding author: Sneh Kiran. Email: drsnehkiran@gmail.com

\begin{abstract}
Introduction and Aim: Isosorbide mononitrate, a nitric oxide donor, induces the enzyme cyclo-oxygenase-2, leading to production of local prostaglandins in human cervix and leads to structural rearrangement of the collagen network and thereby the cervix ripens. The aim of this study was to determine the role of Isosorbide mononitrate in induction of labour, determine induction delivery interval and obstetric and neonatal outcome.
\end{abstract}

Materials and Methods: This study was an interventional study on 40 pregnant women conducted for a period of one year. Women requiring induction of labour, who met the inclusion criteria, were enrolled. Isosorbide mononitrate (40 milligrams) was inserted in the posterior fornix. If Bishop's score did not change after 24 hours of the initial dose, failure of induction of labour was considered. Those patients in whom labour pains started after isosorbide mononitrate alone were considered to be in successful group(A) while those who required additional drugs like prostaglandins were considered to be in the failed group $(F)$.

Results: The mean (SD) Bishop score after 1dose of isosorbide mononitrate in the successful group (A) was 6.04 (2.16) and in the failed group (F) was $3.81(0.83)$. There was a significant difference in terms of Bishop Score after $1^{\text {st }}$ Dose of IMN ( $\left.\mathrm{W}=310.000, \mathrm{p}=0.001\right)$ and in terms of induction-delivery time in hours $(\mathrm{t}=-2.386, \mathrm{p}=0.023)$.

Conclusion: This study concludes that Isosorbide mononitrate has significant role for induction of labor in terms of Bishop score changes and induction delivery interval.

Keywords: Isosorbide mononitrate; cervical ripening; induction of labour; Bishop score.

\section{INTRODUCTION}

I nduction implies stimulation of contractions before the spontaneous onset of labour, with or without rupture of membranes (1). With recent advances in fetal as well as maternal monitoring antenatally, the indications for induction of labour is increasing. Also, resource-constrained facilities refer high risk patients to higher centres, leading to more inductions at tertiary hospitals (2). Most important factor guiding successful induction is condition of cervix i.e., Bishop's score (3). In case of Intrauterine fetal death, mode of birth is largely dependent on fetal gestational age and maternal clinical history, with consideration of the couple's personal preference (4). There is a basket of choices for ripening of cervix, such as oxytocin infusion, intracervical Foley's catheter insertion, intravaginal prostaglandins analogue like misoprost and Dinoprostone gel.

Isosorbide mononitrate, a nitric oxide donor, induces the enzyme cyclo-oxygenase-2, leads to production of local prostaglandins in human cervix and structural rearrangement of the collagen network and thereby the cervix ripes (5-7). This drug does not cause uterine hyperstimulation as is met with prostaglandin analogues. Thus, fetal distress is less observed compared to prostaglandin analogue. It can also be used in induction of labour in those with scarred uterus (8-11). Side effects of isosorbide mononitrate are few like nausea, vomiting, light-headedness (12). Use with vasodilating drugs like sildenafil is contraindicated $(13,14)$. The aim and objectives of our study were to determine the role of isosorbide mononitrate in induction of labour, induction delivery interval and obstetric and neonatal outcome.

\section{MATERIALS AND METHODS}

This interventional study was conducted on 40 pregnant women in Department of Obstetrics and Gynaecology, Indira Gandhi Institute of Medical Sciences, Patna for duration of one year. The study was approved by the Institutional Research Ethics Committee, IGIMS, Patna (494/IEC/2018/ IGIMS) and was registered in Clinical Trials registry (CTRI/2019/07/020011). The research was conducted according to the principles expressed in the Declaration of Helsinki, and all participants were adequately informed about the objectives of study stating their consent to participate by taking written informed consent.

Inclusion criteria were patients with period of gestation >34 weeks, singleton pregnancy with cephalic presentation, Bishop's score $<6$, 
preeclampsia, Intrauterine growth retardation, $\mathrm{Rh}$ negative pregnancy, Intrauterine fetal death and premature rupture of membrane. Exclusion criteria were placenta previa, fetal distress, multiple pregnancy, heart disease, liver disease, malpresentations and sildenafil users.

Women requiring induction of labour, who met the inclusion criteria, were enrolled. Detailed history, general and obstetrical examination was taken. Vaginal examination was done to rule out cephalopelvic disproportion and to assess the Bishop's score. Confirmation of gestational age was done by Naegle's formula and first trimester ultrasonography. Ultrasonography was done in labour room to assess amniotic fluid index, period of gestation, estimated fetal weight and reconfirm fetal presentation and placental localisation.

Complete blood count, maternal blood grouping, routine examination of urine, blood sugar levels and viral markers were done, if not done before. Admission Non stress test as taken.

After taking consent, Isosorbide mononitrate (40 milligrams) was inserted in the posterior fornix. Second dose was repeated after 6 hours, if needed. Fetal heart rate and uterine contraction monitoring were done according to standard guidelines. Maternal pulse rate and blood pressure were also monitored. After 12 hours, if cervix was more than $3 \mathrm{~cm}$ dilated, oxytocin infusion was started at the rate of $2 \mathrm{mU} / \mathrm{min}$ with increments of $2 \mathrm{mU} / \mathrm{min}$ every 30 minutes up to a maximum dose of $8 \mathrm{mU} / \mathrm{min}$. If Bishop's score did not change after 24 hours of the initial dose, failure of induction of labour was considered. Depending upon the reason of induction, prostaglandin analogue PGE2, 2 doses was given if not contraindicated. LSCS was done for fetal distress or other obstetric indications.

Different outcomes measured were changes in Bishop Score, Induction-Delivery interval, Mode of delivery (spontaneous vaginal, instrumental vaginal or LSCS), Neonatal outcome (APGAR score, Birth weight and Neonatal intensive care unit admission).

\section{Statistical analysis}

Sample size calculation:

The sample size was calculated

$$
\begin{array}{|l|l|}
\hline \text { Sample size } \mathrm{N}= & 4 * \mathrm{Z}_{\alpha}{ }^{2} \sigma^{2} / \delta^{2} \\
\hline
\end{array}
$$

The sample size for the study was based on a study by Agarwal et al., (16) who reported the mean change in Bishop's score as follows:

\begin{tabular}{|l|l|l|}
\hline & Mean & SD \\
\hline $\begin{array}{l}\text { Mean change in } \\
\text { Bishop's score }\end{array}$ & 3.2 & 1.61 \\
\hline
\end{tabular}

$\mathrm{Z}_{\alpha}=1.96$

$\sigma=$ reported standard deviation $=1.61$

$\delta=$ width of the $95 \%$ CI (precision) $=1$

Based on the formula given above, using the mentioned values, the sample size required is:

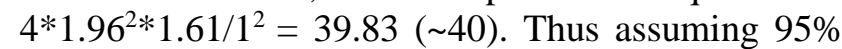
confidence interval of 1 , the proposed sample size for the study is 40 .

Data were recorded in MS Excel spreadsheet program. SPSS v23 (IBM Corp.) was used for data analysis. Descriptive statistics were elaborated in the form of means/standard deviations and medians/IQRs for continuous variables, and frequencies and percentages for categorical variables. Group comparisons for continuously distributed data were made using independent Student's ' $t$ ' test when comparing two groups, and one-way ANOVA when comparing more than two groups. Post-Hoc pairwise analysis was performed using Tukey's HSD test in case of one-way ANOVA. Chi-squared test was used for group comparisons for categorical data. Paired categorical variables were compared using the McNemar's test. Linear correlation between two continuous variables was explored using Pearson's correlation. Statistical significance was kept at $\mathrm{p}<$ 0.05 .

\section{RESULTS}

The mean (SD) age (years) in the induction with IMN alone: Successful (A) group was 25.12 (2.92). The mean (SD) age (years) in the induction with IMN alone: Failed (F) group was 25.25 (4.12). 65.2\% of the participants in the succeeded group were primigravida. $34.8 \%$ of the participants were multigravida. There was no significant difference between the various groups in terms of age $(t=-$ $0.105, \mathrm{p}=0.917)$ and parity $\left(\mathrm{X}^{\wedge} 2=0.321, \mathrm{p}=\right.$ 0.571). (Table-1)

$45.8 \%$ of the participants in the succeeded group were of term pregnancy and $54.2 \%$ were of postdated. There was no significant difference between the various groups in terms of period of gestation $\left(\mathrm{X}^{\wedge} 2=0.017, \mathrm{p}=0.897\right)$.

Table 1: Association between induction with IMN alone and parameters

\begin{tabular}{|c|c|c|c|}
\hline \multirow{2}{*}{ Parameters } & \multicolumn{2}{|c|}{ Induction with IMN Alone } & \multirow{2}{*}{ value } \\
\cline { 2 - 3 } & Succeeded (n= 24) & Failed (n = 16) & \\
\hline Age (Years) & $25.12 \pm 2.92$ & $25.25 \pm 4.12$ & $0.917^{1}$ \\
\hline Age & & & $0.195^{2}$ \\
\hline$<30$ Years & $22(91.7 \%)$ & $12(75.0 \%)$ & \\
\hline$>30$ Years & $2(8.3 \%)$ & $4(25.0 \%)$ & \\
\hline Parity & & & $0.571^{3}$ \\
\hline Primigravida & $15(62.5 \%)$ & $9(56.2 \%)$ & \\
\hline
\end{tabular}




\begin{tabular}{|c|c|c|c|}
\hline Multigravida & $8(33.3 \%)$ & $7(43.8 \%)$ & \\
\hline Period of gestation & & & $0.897^{3}$ \\
\hline Term & $11(45.8 \%)$ & $7(43.8 \%)$ & \\
\hline Post-Dated & $13(54.2 \%)$ & $9(56.2 \%)$ & \\
\hline NST (Reactive) & $24(100.0 \%)$ & $16(100.0 \%)$ & $1.000^{3}$ \\
\hline Bishop Score (Admission) & $2.92 \pm 1.28$ & $2.12 \pm 1.02$ & $0.122^{4}$ \\
\hline Bishop Score (After 1 Dose of IMN)*** & $6.04 \pm 2.16$ & $3.81 \pm 0.83$ & $0.001^{4}$ \\
\hline Mode of Delivery & & & $0.249^{2}$ \\
\hline Vaginal & $17(70.8 \%)$ & $13(81.2 \%)$ & \\
\hline AVD & $0(0.0 \%)$ & $1(6.2 \%)$ & \\
\hline LSCS & $7(29.2 \%)$ & $2(12.5 \%)$ & \\
\hline APGAR (1 Minute) & $7.82 \pm 0.91$ & $7.67 \pm 1.40$ & $0.974^{4}$ \\
\hline APGAR (5 Minute) & $9.36 \pm 0.58$ & $9.21 \pm 0.70$ & $0.560^{4}$ \\
\hline NICU Admission (Required) & $0(0.0 \%)$ & $2(12.5 \%)$ & $0.154^{2}$ \\
\hline Headache (Present) & $5(20.8 \%)$ & $7(43.8 \%)$ & $0.166^{2}$ \\
\hline
\end{tabular}

*** Significant at $\mathrm{p}<0.05,1$ : t-test, 2: Fisher's Exact Test, 3: Chi-Squared Test, 4: Wilcoxon Test

NST: Non-stress test; LSCS: Lower segment Caesarean section; APGAR: Appearance, Pulse, Grimace, Activity, and Respiration; NICU: Neonatal intensive care unit

Table 2: Association between Induction with IMN Alone and Indication for Induction $(\mathrm{n}=40)$

\begin{tabular}{|c|c|c|c|c|c|}
\hline \multirow{2}{*}{$\begin{array}{c}\text { Indication For } \\
\text { Induction }\end{array}$} & \multicolumn{3}{|c|}{ Induction with IMN Alone } & \multicolumn{2}{|c|}{ Fisher's Exact Test } \\
\hline & Successful (A) & Failed $(\mathbf{F})$ & Total & $X^{\wedge} \mathbf{2}$ & P Value \\
\hline CKD & $1(4.2 \%)$ & $0(0.0 \%)$ & $1(2.5 \%)$ & \multirow[t]{12}{*}{11.857} & \multirow[t]{12}{*}{0.294} \\
\hline Diabetes & $1(4.2 \%)$ & $0(0.0 \%)$ & $1(2.5 \%)$ & & \\
\hline Hypertension & $2(8.3 \%)$ & $0(0.0 \%)$ & $2(5.0 \%)$ & & \\
\hline Hypertension+IHCP & $0(0.0 \%)$ & $1(6.2 \%)$ & $1(2.5 \%)$ & & \\
\hline IHCP & $2(8.3 \%)$ & $2(12.5 \%)$ & $4(10.0 \%)$ & & \\
\hline IUGR & $1(4.2 \%)$ & $0(0.0 \%)$ & $1(2.5 \%)$ & & \\
\hline Oligohydramnios & $2(8.3 \%)$ & $4(25.0 \%)$ & $6(15.0 \%)$ & & \\
\hline Post-dated Pregnancy & $13(54.2 \%)$ & $9(56.2 \%)$ & $21(47.5 \%)$ & & \\
\hline Preeclampsia & $0(0.0 \%)$ & $1(6.2 \%)$ & $1(2.5 \%)$ & & \\
\hline Previous IUD & $0(0.0 \%)$ & $1(6.2 \%)$ & $1(2.5 \%)$ & & \\
\hline PROM & $3(12.5 \%)$ & $0(0.0 \%)$ & $3(7.5 \%)$ & & \\
\hline Total & $24(100.0 \%)$ & $16(100.0 \%)$ & $40(100.0 \%)$ & & \\
\hline
\end{tabular}

CKD: Chronic kidney disease; IHCP: Intra hepatic cholestasis of pregnancy; IUGR: Intrauterine growth restriction; IUD: Intra uterine device; PROM: Premature rupture of membrane.

The most common indication for induction is postdated pregnancy $(54.2 \%)$. Some participants had more than one indication like Post-dated pregnancy with oligohydramnios. There was no significant difference between the various groups in terms of Indication for Induction $\left(X^{\wedge} 2=11.857, p=0.294\right)$. (Table 2) Admission NST prior to induction was reactive in all patients.

The mean (SD) Bishop Score at the time of admission in the successful (A) group was 2.92 (1.28) and in the failed (F) group was 2.12 (1.02).
There was no significant difference between the groups in terms of Bishop Score at the time of admission ( $\mathrm{W}=246.000, \mathrm{p}=0.122$ ). The mean $(\mathrm{SD})$ Bishop Score after 1 Dose of IMN in the group A was 6.04 (2.16) and in the failed group was 3.81 (0.83). There was a significant difference between the 2 groups in terms of Bishop Score after $1^{\text {st }}$ Dose of IMN $(\mathrm{W}=310.000, \mathrm{p}=0.001)$, with the median Bishop Score after $1^{\text {st }}$ Dose of IMN being highest in the successful (A) group.

Table 3: Comparison of the 2 subgroups of the variable induction with IMN alone in terms of induction-delivery time in hours $(\mathrm{n}=40)$

\begin{tabular}{|c|c|c|c|c|}
\hline \multirow{2}{*}{$\begin{array}{c}\text { Induction-Delivery } \\
\text { Time (Hours) }\end{array}$} & \multicolumn{2}{|c|}{ Induction with IMN Alone } & \multicolumn{2}{|c|}{ t-test } \\
\cline { 2 - 3 } Successful (A) & Failed (F) & T & p value \\
\hline Mean (SD) & $20.83(8.52)$ & $27.59(8.95)$ & -2.386 & 0.023 \\
\hline Median (IQR) & $21.25(10.75)$ & $28(15.25)$ & & \\
\hline Range & $8-36$ & $14-42$ & & \\
\hline
\end{tabular}

SD: Standard deviation; IQR: interquartile range.

The mean (SD) Induction-Delivery Time in hours in the successful (A) group was 20.83 (8.52) and in the failed (F) group was 27.59 (8.95). There was a significant difference between the 2 groups in terms of Induction-Delivery Time (Hours) $(\mathrm{t}=-2.386, \mathrm{p}=$ 
0.023), with the mean Induction-Delivery Time (Hours) being highest in the failed group. (Table-3)

$70.8 \%$ of the participants' in-group A had vaginal delivery and $29.2 \%$ of the participants delivered by LSCS. $81.2 \%$ of the participants in group $\mathrm{F}$ had vaginal delivery, $6.2 \%$ by applying outlet forceps and $12.5 \%$ of the participants delivered by LSCS. There was no significant difference between the various groups in terms of distribution of mode of delivery $\left(\mathrm{X}^{\wedge} 2=2.824, \mathrm{p}=0.249\right)($ Table-1).

The mean (SD) APGAR score (1 Minute) in the successful group was $7.82(0.91)$ and in the failed group was 7.67 (1.40). The mean (SD) of APGAR (5 Minute) in the successful group was $9.36(0.58)$. The mean (SD) of APGAR (5 Minute) in the Failed group was $9.21(0.70)$. There was no significant difference between the groups in terms of APGAR (1 Minute) $(\mathrm{W}=163.500, \mathrm{p}=0.974)$ and APGAR (5 Minute) $(\mathrm{W}=170.500, \mathrm{p}=0.560)$. (Table-1)

$20.8 \%$ of the participants' in-group A had headache requiring analgesics. There was no significant difference between the various groups in terms of distribution of headache $\left(\mathrm{X}^{\wedge} 2=2.401, \mathrm{p}=0.166\right)$.

\section{DISCUSSION}

The induction of labour requires when the risks overweigh the benefits of continuing pregnancy. The condition or the favourability of cervix is an important prognostic factor in the success of induction of labour. Several studies are being done to identify the ideal cervical ripening agent. A significant number of women complained of headache but all responded to analgesics.

In our study, the mean (SD) Bishop Score after 1Dose of IMN in group A was 6.04 (2.16) and in the failed group $(\mathrm{F})$ was $3.81(0.83)$. There was a significant difference in terms of Bishop Score after $1^{\text {st }}$ Dose of IMN ( $\left.\mathrm{W}=310.000, \mathrm{p}=0.001\right)$. The results were comparable to other studies like Bollapragada et al., (10) who concluded that IMN as a preinduction cervical ripening agent was minimal. Though in their study, IMN had a significant effect on the change in cervical Bishop Score (mean difference of 0.65, $\mathrm{p}=0.013$ ). Bishop Score changes were greater in Osman et al., (15) and Agarwal et al., (16) $(3.17 \pm 2.02 \mathrm{v} / \mathrm{s} 0.25 \pm 0.93, \mathrm{P} \leq 0.001)$. Habib et al., (11) also found significantly shorter admission to delivery intervals in the IMN group in contrast to placebo.

Similarly in Agarwal et al., (16) in which meantime from admission to delivery was $(9.7 \pm 5.28 \mathrm{v} / \mathrm{s}$ $13.49 \pm 4.35$ hours $)(\mathrm{P} \leq 0.001)$ and in Eddama et al., (14) $(25.06 \mathrm{v} / \mathrm{s} 26.66$ hours) ( $\mathrm{P}=0.37)$. According to Eddama et al., there was no significant difference, because all patients, which selected were nulliparous and this study conducted mainly for cost effectiveness of drug.
There was no significant difference between the various groups in terms of distribution of mode of delivery $\left(\mathrm{X}^{\wedge} 2=2.824, \mathrm{p}=0.249\right)$. Most of the studies such as those conducted by Agarwal et al., (16) and Habib et al., (11) have shown lower incidence of caesarean deliveries in IMN group albeit statistically insignificant.

$20.8 \%$ of the participants in the succeeded group had headache requiring analgesics. There was no significant difference between the various groups in terms of distribution of headache $\mathrm{X}^{\wedge} 2=2.401, \mathrm{p}=$ 0.166). In Agarwal et al., (16) study, 63\% patients had mild headache in IMN group and $10 \%$ were required medication.

None of the neonate's in-group A of our study required NICU admission. In study done by Krishnamurthy et al., (17), only 1 neonate was admitted in NICU and discharged after 2 days.

The limitation of our study was its small sample size and so further research is needed on a larger population so that results can be externally validated.

\section{CONCLUSION}

Labour induction is needed by many pregnant women. Though prostaglandin gel is considered to be quite effective in inducing labour, this study shows the utility of Isosorbide mononitrate as cervical ripening and labour inducing agent. This drug is cheap and does not require refrigeration. These are its advantages over Prostaglandin gel. Fetal distress is often seen with prostaglandins. But in this study, Isosorbide Mononitrate proved to be safe for the neonate. Headache is one significant side-effect which the patients need to be counselled beforehand and is amenable to treatment.

\section{CONFLICT OF INTEREST}

Authors declare no conflict of interest.

\section{REFERENCES}

1. Cunningham, F. G., Leveno, K. T., Bloom, S. L., Hauth, J. C., Rouse, D. J., Spong, C. Y. Labor induction. Williams Obstetrics. 23rd edition. New York:McGraw-Hill Medical, 2010.

2. Abdellah, M. S., Hussein, M., Aboalhassan, A. Intravaginal administration of isosorbide mononitrate and misoprostol for cervical ripening and induction of labor: A randomized controlled trial. Arch Gynecol Obstet. 2011; 284: 25-30. [Pub Med]

3. Shi, L., Shi, S. Q., Saade, G. R., Chawalisz, K., Garfield, R. E. Studies of cervical ripening in pregnant rats: Effect of various treatments. Mol Hum Reprod. 2000; 6: 382-389. [PubMed]

4. Koopmans, L., Wilson, T., Cacciatore, J., Flenady, V. Support for mothers, fathers and families after perinatal death. Cochrane Database Syst Rev 2013; 6: CD000452. Pmid: 23784865

5. Chawalisz, K., Garfield, R. E. Nitric oxide as the final mediator of cervical ripening. Hum Reprod. 1998; 13: 245 248.

6. Väisänen-Tommiska, M. Nitric oxide in human uterine cervix: role in cervical ripening. academic dissertation, 
Department of Obstetrics and Gynaecology, Faculty of Medicine, Institute of Clinical Medicine, University of Helsinki. Finland. 2006: 19-23.

7. Ledingham, M. A., Denison, F. C., Kelly, R. W., Young, A., Norman, J. E. Nitric oxide donors stimulate prostaglandin F ( 2 alpha) and inhibit thromboxane B (2) production in the human cervix during the first trimester of pregnancy. Mol Hum Reprod. 1999; 5: 973-982. [Pub Med]

8. Ekerhovd, E., Bullarbo, M., Andersch, B., Norström, A. Vaginal administration of the nitric oxide donor isosorbide mononitrate for cervical ripening at term: A randomized controlled study. Am J Obstet Gynecol. 2003; 189: 16921697. [Pub Med]

9. Chawalisz, K., Garfield, R. E. Regulation of the uterus and cervix during pregnancy and labor. Role of progesterone and nitric oxide. Ann N Y Acad Sci. 1997; 26: 238-253.

10. Bollapragada, S. S., Mackenzie, F. Randomized placebocontrolled trial of outpatient (at home) cervical ripening with Isosorbide Mononitrate (IMN) prior to induction of labor-clinical trial with analyses of efficacy and acceptability: The IMOP study. ObstetGynecolSurv. 2009; 64: 699-700. [Pub Med]

11. Habib, S. M., Emam, S. S., Saber, A. S. Outpatient cervical ripening with nitric oxide donor isosorbide mononitrate prior to induction of labor. Int J Gynaecol Obstet. 2008; 101: 57-61. [Pub Med]

12. Rameez, M. F., Goonewardene, I. M. Nitric oxide donor isosorbide mononitrate for pre-induction cervical ripening at 41 weeks' gestation: A randomised controlled trial. J Obstet Gynaecol Res. 2007; 33: 452-456. [Pub Med]

13. Bullarbo, M., Orrskog, M. E., Andersch, B., Granström, L., Norström, A., Ekerhovd, E. Outpatient vaginal administration of the nitric oxide donor isosorbide mononitrate for cervical ripening and labor induction postterm: A randomized controlled study. Am J Obstet Gynecol. 2007; 196: e1-5. [Pub Med]

14. Eddama, O., Petrou, S., Schroeder, L., Bollapragada, S. S., Mackenzie, F., Norrie, J., et al., The cost-effectiveness of outpatient (at home) cervical ripening with isosorbide mononitrate prior to induction of labour. BJOG. 2009; 116: 1196-1203. [Pub Med]

15. Osman, I., MacKenzie, F., Norrie, J., Murray, H. M. The "PRIM" study: a randomized comparison of prostaglandin E2 gel with the nitric oxide donor isosorbide mononitrate for cervical ripening before the induction of labor at term. Am J Obstet Gynecol. 2006; 194(4): 1012-1021.

16. Agarwal, K., Batra, A., Batra, A., Dabral, A., Aggarwal, A. Evaluation of isosorbide mononitrate for cervical ripening prior to induction of labour for post-dated pregnancy in an outpatient setting. Int J Gynaecol Obstet. 2012; 118(3): 205209.

17. Krishnamurthy, R., Pallavee, P., Ghose, S. Evaluation of isosorbide mononitrate for preinduction of cervical ripening: A randomized placebo-controlled trial. J Family Reprod Health. 2015; 9: 75-81. 